\title{
Coupling inter-patch movement models and landscape graph to assess functional connectivity
}

\author{
Benjamin Bergerot $\cdot$ Pierline Tournant $\cdot$ Jean-Pierre Moussus • \\ Virginie-M. Stevens • Romain Julliard • Michel Baguette • \\ Jean-Christophe Foltête
}

Received: 12 April 2012/Accepted: 16 October 2012/Published online: 15 November 2012

(C) The Society of Population Ecology and Springer Japan 2012

\begin{abstract}
Landscape connectivity is a key process for the functioning and persistence of spatially-structured populations in fragmented landscapes. Butterflies are particularly sensitive to landscape change and are excellent model organisms to study landscape connectivity. Here, we infer functional connectivity from the assessment of the selection of different landscape elements in a highly fragmented landscape in the Île-de-France region (France). Firstly we measured the butterfly preferences of the Large White butterfly (Pieris brassicae) in different landscape elements using individual release experiments. Secondly, we used an inter-patch movement model based on butterfly choices to build the selection map of the landscape elements to moving butterflies. From this map, functional connectivity network of $P$. brassicae was
\end{abstract}

B. Bergerot $(\bowtie) \cdot$ J.-P. Moussus · R. Julliard · M. Baguette CNRS-MNHN-PARIS VI UMR 7204'Conservation des Espèces, Restauration et Suivi des Populations', CRBPO, 55 Rue Buffon, CP 51, 75005 Paris, France

e-mail: bergerot@mnhn.fr

\section{B. Bergerot}

Hepia, Centre de Lullier, University of Applied Sciences Western Switzerland, Technology, Architecture and Landscape, Route de Presinge 150, 1254 Jussy, Switzerland

P. Tournant · J.-C. Foltête

CNRS-UMR ThéMA 6049, Université de Franche-Comté,

32 rue Mégevand, 25030 Besançon Cedex, France

\section{V.-M. Stevens}

F.R.S. FNRS, Unité de Biologie Du Comportement, Université de Liège, 22 quai Van Beneden, 4020 Liège, Belgium

V.-M. Stevens - M. Baguette

CNRS USR 2936 'Station d'écologie expérimentale du CNRS, 09200 Moulis, France modelled using landscape graph-based approach. In our study area, we identified nine components/groups of connected habitat patches, eight of them located in urbanized areas, whereas the last one covered the more rural areas. Eventually, we provided elements to validate the predictions of our model with independent experiments of mass release-recapture of butterflies. Our study shows (1) the efficiency of our inter-patch movement model based on species preferences in predicting complex ecological processes such as dispersal and (2) how interpatch movement model results coupled to landscape graph can assess landscape functional connectivity at large spatial scales.

Keywords Dispersal · Fragmented landscape . Inter-patch movement modelling · Lepidoptera .

Pieris brassicae · Urbanization

\section{Introduction}

Habitat fragmentation is defined as the emergence of discontinuities in the habitat of a given species (Wilcove et al. 1986; Fahrig 2003; Haddad and Tewksbury 2005). From an organism's viewpoint, the fragmentation process creates a patchwork of suitable habitats separated by a matrix of landscape elements that are more or less hospitable according to their resource availability or permeability to movements. As habitat patches are often too small to sustain viable populations, the persistence of many species in fragmented landscapes relies on dispersal, i.e., the movements of individuals which maintain gene flow between local populations, rescue declining populations or allow recolonizations after local extinction (Fahrig and Merriam 1994; Haddad 1999; Hanski 1999). 
Landscape connectivity describes how elements making up a given landscape will facilitate or impede the movements of dispersing individuals (e.g., Taylor et al. 1993). The mechanistic understanding of the dispersal process is an essential prerequisite to the assessment of landscape connectivity. Dispersal can be considered as a three-stage process: (1) the decision of leaving a suitable habitat, (2) the transience through more or less hospitable landscape elements and (3) the settlement in an empty habitat or a local population (Stevens et al. 2010). As various costs and benefits are associated to each of these stages, they are under uncoupled selection pressures (Baguette and Van Dyck 2007; Clobert et al. 2009), which hinders wide generalizations but rather makes functional landscape connectivity population specific. Functional connectivity ultimately results from habitat selection by dispersing individuals (i.e., their choice at the border between landscape elements). Dispersal is itself controlled by the permeability of each landscape element (i.e., the relative costs and benefits associated to their crossing; e.g., Stevens et al. 2006). Consequently, considering functional connectivity requires dealing with individuals' dispersal fluxes. If dispersal events are difficult to observe directly, dispersal connectivity can be estimated using techniques such as cost-distance modelling, individual based models or landscape genetics (Baguette and Van Dyck 2007; Spear et al. 2010; Storfer et al. 2010). Landscape graphs modelling (applied from graph theory, Bunn et al. 2000, Urban and Keitt 2001) has been proposed as an appealing addition to these approaches and was used in many ecological studies dealing with landscape connectivity for conservation purposes (Saura and Pascual-Hortal 2007; Andersson and Bodin 2009; Foltête et al. 2012). This method, based on the metapopulation concept, allows modeling and measuring the potential functional connectivity by taking into account the whole network in a given landscape (Urban et al. 2009; Galpern et al. 2011). The landscape is modelled as a graph considering the optimal habitat patches for the focal species as the nodes of the network and links between nodes represent paths connecting habitat patches, based on ecological assumptions about the movements of the species within the landscape.

In this study, landscape graph modelling was associated with an inter-patch movement model to assess the level of functional connectivity between habitat patches (i.e., physical areas used by an organism or by a community of different organisms, Morrison and Hall 2002) among landscape elements (i.e., all other physical areas which surround habitat patches) of an urbanized landscape around Paris in the Île-de-France region (France). More specifically, we intend to define and delineate graph components (i.e., a group of connected nodes, isolated from other components, also called a subgraph, Fall et al. 2007) within this region for a study species, the Large White butterfly ( $P$. brassicae) and to test the relevance of these graph components with empirical data from field study.

First, we experimentally assessed the landscape element selection of individual butterflies. We released butterflies at selected locations that offered choices between landscape elements. Using the results of these experiments, we built a transition matrix of the selections between landscape elements. Second, we used a graph-based approach to identify graph components of highly connected habitat patches in the region. Predictions were validated by using a mass release experiment of marked individuals. We expected that released individuals will move more often between well connected habitat patches than between randomly chosen landscape elements.

\section{Materials and methods}

Study species and rearing conditions

Pieris brassicae is a common and widespread species across Europe (Bink 1992), which is present in the urbanized region of Île-de-France (Bergerot et al. 2010a). We bred individuals in the lab by placing adults captured in the region in an oviposition cage $(80 \times 80 \times 80 \mathrm{~cm})$ with cabbage leaves (Brassica oleracea L.) under incandescent light to maintain a $14 \mathrm{~L}$ : 10D photoregime. A honey-water solution (1:10 flower honey, 9: 10 water) in Eppendorf tube was provided ad libitum as a source of carbohydrate, and water was supplied through a soaked sponge. To produce synchronized batches of young larvae, oviposition plants were changed every 2 days. Eggs on plants were held in a growth chamber at $23{ }^{\circ} \mathrm{C}$ and $50 \%$ relative humidity until larvae hatched and reached the adult stage. We then used adult butterflies in the experiment.

\section{Individual release procedure and habitat selection}

Three release sites near Paris (France) were used to collect individual data of habitat choice by butterflies in urbanized landscapes (Fig. 1a). Each site was a $30 \mathrm{~m}$ diameter roundabout covered with gravel without any tree (so without any shaded area) or flowers (which could be attractive for the butterflies). Each roundabout provided access to different landscape elements with similar area, hence offering the opportunity to select specific landscape elements. As butterflies had to leave the roundabout, they had to perform direct, oriented movements to enter a given landscape element. Site 1 (IRS 1: $48^{\circ} 49^{\prime} 37.63^{\prime \prime} \mathrm{N}-$ $2^{\circ} 25^{\prime} 50.59^{\prime \prime} \mathrm{E}$ ) offered escape through 6 landscape elements: lawn, shaded lawn (by trees), artificial area, shaded artificial area (by trees), forest edge and wastelands 


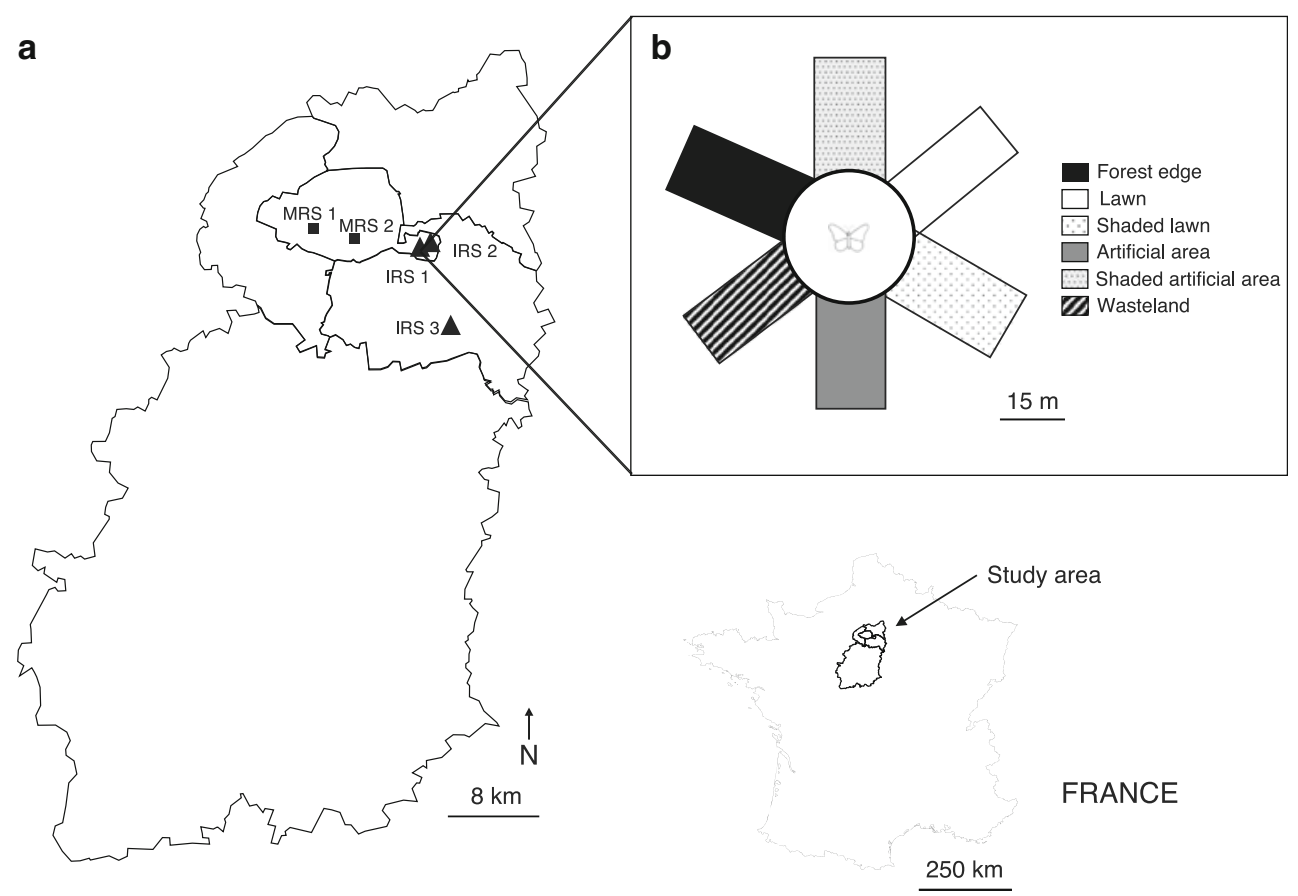

Fig. 1 Location of a the three individual release sites (IRS) and the two MRS used in the Île-de-France region. b: IRS 1: roundabout with 6 landscape elements

(Fig. 1b). Site 2 (IRS 2: $\left.48^{\circ} 50^{\prime} 5.11^{\prime \prime} \mathrm{N}-2^{\circ} 26^{\prime} 16.18^{\prime \prime} \mathrm{E}\right)$ offered escape through 4 different landscape elements: lawn, shaded lawn, artificial area and shaded artificial area. Finally, site 3 (IRS 3: $48^{\circ} 43^{\prime} 48.03^{\prime \prime} \mathrm{N}-2^{\circ} 31^{\prime} 14.32^{\prime \prime} \mathrm{E}$ ) offered 4 exits made of only two different landscape elements: lawn and shaded lawn.

We standardized the release procedure as much as possible. First, to insure comparable feeding status among butterflies, butterflies were food-deprived during $12 \mathrm{~h}$ and then fed them ad libitum with honey-water solution (1/10 honey, 9/10 water) during $2 \mathrm{~h}$ just before release. Butterflies were placed in individual boxes at $5-6{ }^{\circ} \mathrm{C}$ for transportation between the laboratory and the release sites (15-30 min according to sites) to avoid stress and energy consumption. All releases were performed under optimal weather conditions to ensure butterfly flight activity: wind speed less than $10 \mathrm{~km} / \mathrm{h}$, air temperature $\geq 17{ }^{\circ} \mathrm{C}$ and $100 \%$ sunshine. The low wind speed prevented wind direction from interfering with landscape element selection. For release, each butterfly was individually placed on a take-off platform at the center of the release point, with a random orientation relative to the sun. Then, the butterfly was allowed to warm up for a few minutes in the sun before it left the platform and escape the roundabout. Only effective choice was considered i.e., when the butterfly did not return to the roundabout within $10 \mathrm{~s}$ after crossing its limit. We then recorded the first landscape element in which it entered. The observers remained at a distance $\geq 10 \mathrm{~m}$ from the butterfly to avoid interference with the butterfly's behavior.
Table 1 Butterfly leaving into each habitat (\%) according to the landscape elements present at each release site $(N$ : number of individuals released in each site)

\begin{tabular}{lcll}
\hline & $\begin{array}{l}\text { Site 1 } \\
(N=48)\end{array}$ & $\begin{array}{l}\text { Site 2 } \\
(N=50)\end{array}$ & $\begin{array}{l}\text { Site 3 } \\
(N=50)\end{array}$ \\
\hline Lawn & 20.83 & 26.00 & 32.00 \\
Shaded lawn & 4.17 & 56.00 & 68.00 \\
Artificial area & 2.08 & 4.00 & \\
Shaded artificial area & 22.92 & 14.00 & \\
Wastelands & 6.25 & & \\
Forest edge & 43.75 & & \\
\hline
\end{tabular}

We performed three release sessions in 2009 at each site, at the end of May, mid-June and mid-July. In total, 48, 50 and 50 butterflies were released at sites 1, 2 and 3 respectively. Each session lasted 2 days in order to perform the individual releases between $11.30 \mathrm{am}$ and $14.30 \mathrm{pm}$ in specific weather conditions mentioned above. The order of the sites was randomly chosen to avoid an hour effect.

Statistical analyses of butterfly preferences

To test if butterflies used some landscape elements more than others, we compared the choices made at the three sites (Table 1) using odd ratio comparisons. Odds ratio comparisons describe the strength of the association of an event (here the choice of a given landscape element) 


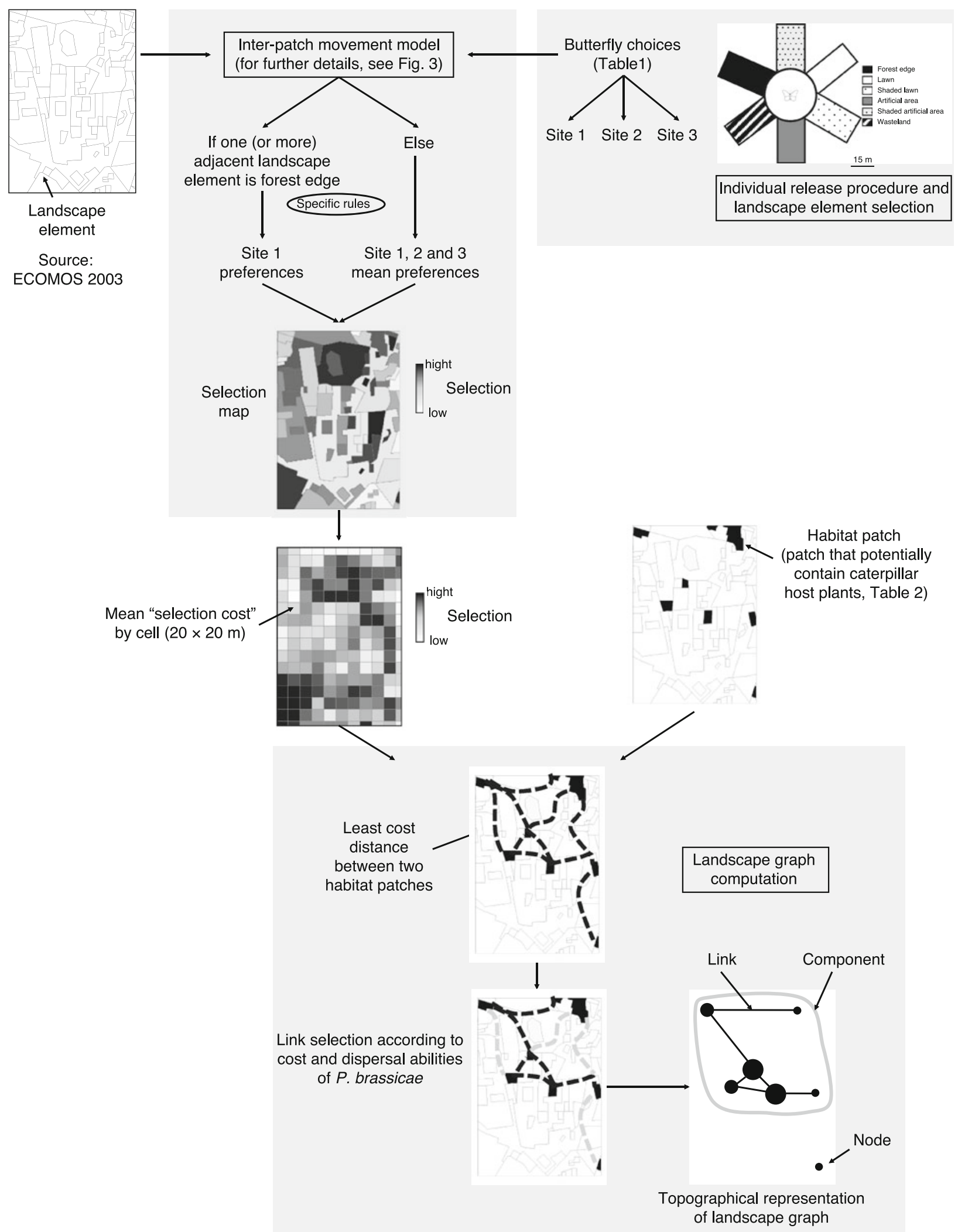

Fig. 2 Steps followed from the individual release procedure to the computation of landscape graph. At the end of the process, the topographical representation of landscape graph contains nodes (i.e., habitat patches, node size is proportional to the number of links). A component represents a group of connected nodes, isolated from other components 
occurring in different groups (e.g., sites). To compare butterfly preferences, we calculated the odds ratio and their associated $P$ values using median-unbiased estimation (med-P).

\section{Inter-patch movement model}

The inter-patch movement model allowed the calculation of "the number of individuals that come into a specific landscape element" (i.e., selection of a landscape element by $P$. brassicae) at the Île-de-France scale to obtain a "selection map" (Fig. 2). More precisely, the model calculated a percentage of individuals that come into a given landscape element according to the nature of the landscape element considered and the nature of the adjacent landscape elements (Fig. 3). Landscape elements data were extracted from the land cover database (ECOMOS 2003, Table 2). To compute the inter-patch model and so obtain the selection map, we simulated the release of 200 butterflies in each landscape element and analyzed the propensity of butterflies to go in the adjacent elements (Fig. 3) based on the butterfly preferences obtained from landscape element selection results (i.e., individual release experiments). In this model, the butterfly had two choices: "stay in the landscape element" or "go in one of the adjacent landscape elements". We thus obtained the percentage of butterflies (out of 200 simulation releases per landscape elements) which stay or leave the landscape element of interest.

The inter-patch movement model follows specific rules (Fig. 2). Firstly, some butterfly preferences could not be tested in the individual release experiment (choice with landscape elements classified as "Others" in Table 2, e.g., from/to inland waters). So in the inter-patch movement model, we attributed the value 1 to butterfly selection between landscape elements classified as "Others" and available groups of landscape elements tested in individual release experiment. By doing this, "Other" landscape elements have no influence in the calculation of landscape element selection.

Secondly, two specific rules (Fig. 2) were used to calculate landscape element selection in the inter-patch

Fig. 3 Procedure of selection (S) calculation for a landscape element (Element) with 200 simulated releases in each adjacent landscape element

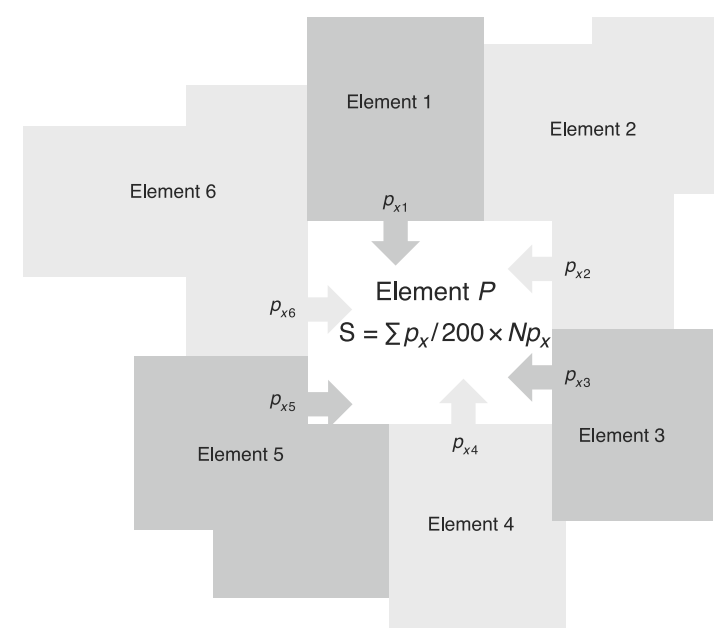

$P_{X(1,2,3,4,5,6)}$ : Butterfly number moving from element $X$ to $P$

Npx: Number of elements surrounding element $P$ S: Element selection

Table 2 Number of landscape elements occurring in the study area following the ECOMOS 2003 classification and their cumulative area (ha)

\begin{tabular}{|c|c|c|c|}
\hline Landscape element & Description & $\begin{array}{l}\text { Number of elements } \\
(\%)\end{array}$ & $\begin{array}{l}\text { Cumulative area } \\
\text { (ha, \%) }\end{array}$ \\
\hline Artificial areas & Tar roads, buildings, parking, houses, railway tracks & $63306(57.79 \%)$ & $79635.74(30.90 \%)$ \\
\hline Shaded lawns & Shaded lawns ${ }^{\mathrm{a}}$ (public and private), cemeteries ${ }^{\mathrm{a}}$, camping ${ }^{\mathrm{a}}$, orchards ${ }^{\mathrm{a}}$ & $24545(22.40 \%)$ & $19765(7.67 \%)$ \\
\hline Wastelands & $\begin{array}{l}\text { Shrubs }{ }^{\mathrm{a}} \text {, industrial and urban wastelands }{ }^{\mathrm{a}} \text {, fallow lands }{ }^{\mathrm{a}} \text {, construction } \\
\text { sites }\end{array}$ & $8255(7.53 \%)$ & $98031.97(38.04 \%)$ \\
\hline Forest edges & Forest edges ${ }^{\mathrm{a}}$, forest ways ${ }^{\mathrm{a}}$ & $6225(5.68 \%)$ & $45665.29(17.72 \%)$ \\
\hline Lawns & $\begin{array}{l}\text { Lawns }^{\mathrm{a}} \text { (in public and private areas), golf courses }{ }^{\mathrm{a}} \text {, racecourses }{ }^{\mathrm{a}} \text {, sport } \\
\text { facilities }^{\mathrm{a}}\end{array}$ & $4135(3.77 \%)$ & $8343.43(3.23 \%)$ \\
\hline Others & Inland waters (rivers, ponds, lakes...) & $2220(2.02 \%)$ & $3131.99(1.22 \%)$ \\
\hline $\begin{array}{l}\text { Shaded artificial } \\
\text { areas }\end{array}$ & Shaded tar roads, shaded parking, artificial shaded canal banks & $872(0.81 \%)$ & $3148.25(1.22 \%)$ \\
\hline
\end{tabular}

${ }^{a}$ Landscape elements that potentially contain P. brassicae host plants and considered as habitat patch 
movement model using results coming from the butterfly preferences (i.e., individual release experiment). For one specific landscape element, we used butterfly preferences derived from butterfly choices at release site 1 (Table 1) if an adjacent landscape element was forest edge, else we used the mean butterfly preferences from all three sites. Indeed, the individual release results showed that the presence of forest edge in one adjacent landscape element significantly modifies butterfly preferences and forest edge was significantly more chosen. In other words, if the surrounding landscape elements included forest edges, butterfly preferences considered in the inter-patch movement model were derived from butterfly preferences at release site 1 , otherwise we used mean selections from all three release sites (1, 2 and 3).

Thirdly, we weighted butterfly selection according to the contact length between adjacent landscape elements. The aim of this step was to take into account the contact length between a specific landscape element and the adjacent landscape elements in the calculation of butterfly selection in the inter-patch movement model. For example, the number of individuals that come in a specific landscape element bordered at $80 \%$ by shaded lawn and $20 \%$ by lawn would be different that the same landscape element bordered at $20 \%$ by shaded lawn and $80 \%$ by lawn. We thus assumed that the butterfly choice would increase with the length of boundary between two adjacent landscape elements.

\section{Mass release-recapture protocol}

To validate our model predictions, we performed two mass releases of $P$. brassicae in 2009. Resightings of marked butterflies were then mainly performed by volunteers made aware of this experiment by wide media coverage (TV, newspapers). Released butterflies were reared in the lab under the same conditions as butterflies used in individual release experiments. Adult butterflies were then placed in transport cages $(1.20 \times 1.20 \times 1.20 \mathrm{~m})$ containing honeywater solution and water $2 \mathrm{~h}$ before the release session (travelling time was 20-35 min according to the location of the release sites).

Two release sessions were performed, in two urban parks: in park 1 in June 2009 and in park 2 in July 2009 under the same weather conditions as those selected for individual releases Each mass release session began at $12.30 \mathrm{pm}$. Both parks were public urban parks (Fig. 1a). Park 1 (MRS 1: $48^{\circ} 51^{\prime} 8.34^{\prime \prime} \mathrm{N}-2^{\circ} 19^{\prime} 5.68^{\prime \prime} \mathrm{E}$ ) was 0.2 ha and park 2 (MRS 2: $48^{\circ} 50^{\prime} 38.68^{\prime \prime} \mathrm{N}-2^{\circ} 21^{\prime} 26.15^{\prime \prime} \mathrm{E}$ ) was 23.5 ha. 26 and 84 butterflies were released in MRS1 and MRS2 respectively.

Each butterfly was marked on the ventral side of both the left and the right hind-wings with fine, non-toxic, permanent makers (Staedler Lumocolor 313, Staedler, Nürnberg, Germany). Butterflies were marked with a symbol associated with a specific colour for each mass release site to increase the detection of reading errors. We did not use individual marks to avoid identification mistakes as much as possible and because we wish to identify a diffusion gradient in the matrix and not to get information on individual trajectories.

\section{Measuring landscape connectivity}

In this study, we defined suitable habitat patches as landscape elements that potentially contain caterpillar host plants (Table 2). We used host plants and not nectar sources because in urban landscapes, adult feeding resources do not represent a main factor explaining butterflies distribution patterns (Bergerot et al. 2010b). As P. brassicae females mainly lay eggs on Brassica and Tropaeolum (Dennis and Hardy 2007), we selected all landscape elements which could contain these host plants in their herb layers in the ECOMOS 2003 classification (Table 2).

Landscape connectivity network was investigated using the landscape graph-based approach, considering the previously defined habitat patches as the node of the graph (Fig. 2, Bunn et al. 2000; Urban and Keitt 2001). Among the different types of existing graphs, we focused on the minimum planar graph (O'Brien et al. 2006; Fall et al. 2007) for which all pairs of nearby nodes are connected by a link based on least-cost distances. Various methods have been proposed to model these inter-habitat patch links and one of the most recurrent is based on least-cost distance because of its greater ecological relevance than Euclidean distance (O'Brien et al. 2006; Fall et al. 2007; Minor and Lookingbill 2010). Based on the selection map obtained by the inter-patch movement model (Fig. 2), we generated a $20 \mathrm{~m}$ resolution grid cell of our study area (Fig. 2) and calculated the mean butterfly selection value of each cell. These values were used to compute the edge-to-edge least cost distance between all pairs of nearby nodes.

As in the studies of O'Brien et al. (2006) and Laita et al. (2011) and in order to test how the landscape graph-based model fits with the empirical data describing the dispersal process, we drew several landscape graphs by successively increasing the length of the least cost distance between nodes (called the threshold distance). This length could correspond to the maximum movement ability for the considered species. Following this method, each landscape graph newly computed contained a specific number of components, i.e., a group of habitat patches potentially interconnected by dispersal movements, functionally isolated from any other group (Urban and Keitt 2001). The threshold distance was initialized at 0 , i.e., corresponding to all the nodes remaining isolated, and was regularly 
increased of 25 cost units until all the nodes were connected into a single component. Between these two extremes, the relevance of each graph was assessed by the rate of intra-component resights, i.e., the proportion of individuals visually recaptured in the same component from where they were released (Fig. 4). Theoretically, we assumed that the higher the proportion, the higher the relevance of the graph. However, as the number of components inherently decreases when the threshold distance increases, we expect a monotonic increase in the proportion of within-component recaptures with increasing threshold distances. To distinguish an effect of landscape connectivity from this artefact, we used a set of randomly generated resighting points to get a pattern purely attributable to this artefact, and then compare observed patterns to this null expectation. The spatial distribution (mean and standard deviation of Euclidean distances to mass release sites (MRS) of those simulated points was the same as the real resighting points. We simulated 100 resighting points for each release site. Random resighting points were computed based on the maximum number of days during which
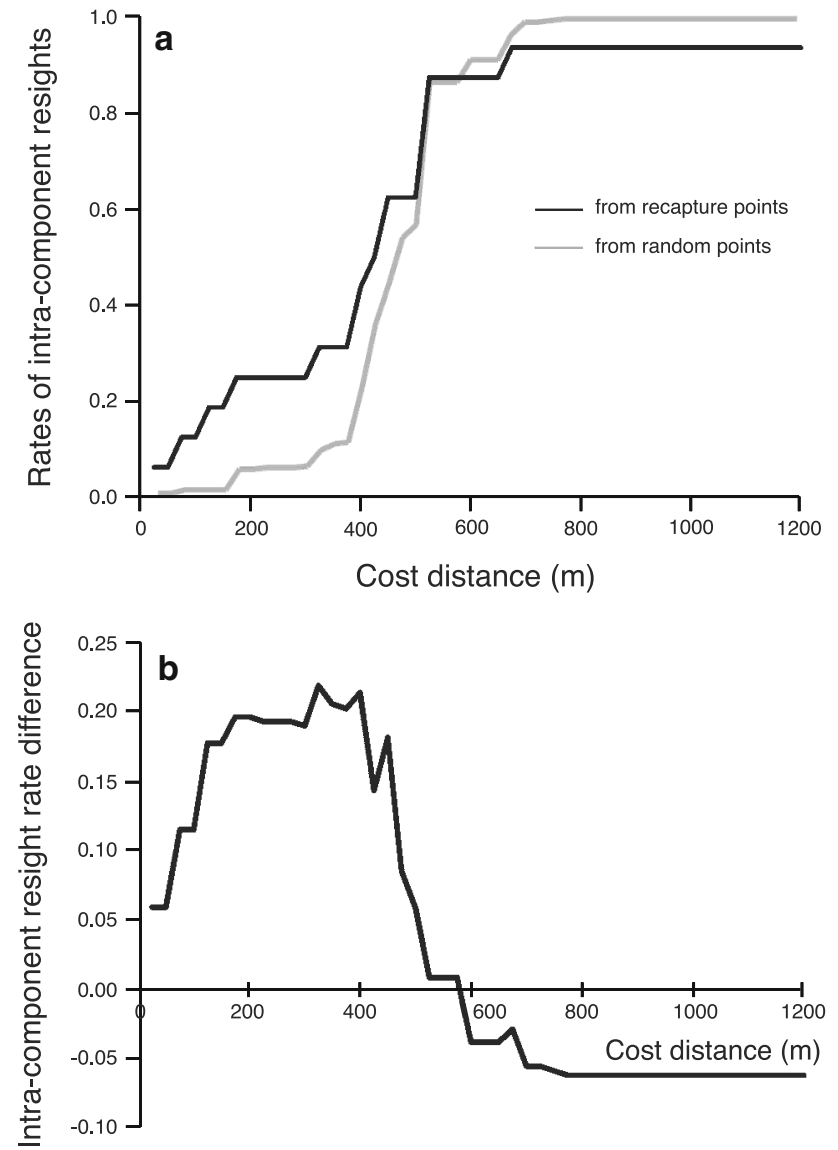

Fig. 4 Rates of intra-component resights from real recapture points (black line) and random recapture points (grey line) according to the cost distance (meters) of landscape graphs (a). Difference between the rates of intra-components resights from real recapture data and random data according to the cost distance (meters) of landscape graphs (b) butterflies were resighted for each release site and the mean daily dispersal distance of $P$. brassicae (i.e., from 3 to 5 daily $\mathrm{km}$ randomly covered, Feltwell 1981). Then, we compared recapture rates in the two series (real and simulated) using $\chi^{2}$ tests according to increasing threshold distances corresponding to decreasing number of components. The most realistic landscape graph provides the maximal difference between the rate of intra-component resights resulting from the observed data and the random sample. Indeed, at this threshold, the selected graph better fitted the data than random simulations. Spatial and statistical analyses were performed with ESRI ArcGis $9.3^{\odot}$ and $\mathrm{R} 2 \cdot 7.0^{\odot}$ respectively.

\section{Results}

Butterfly landscape element selection

Results showed no significant differences between butterfly choices (Table 1) for lawns (same choices at sites 1, 2 and 3 ), artificial areas (sites 1 and 2) and shaded artificial areas (sites 1 and 2). Only two significant differences occurred between sites 1-2 and sites 1-3 (Table 1). Indeed, in sites 2 and 3 , shaded lawns were significantly more chosen than in site 1 (med-P<0.001). In site 1 , forest edges were significantly more chosen than other landscape elements ( $\chi^{2}$ test, $\left.\chi^{2}=36.5, d f=5, P<0.001\right)$. Thus, when forest edges were available (site 1), butterflies preferentially chose this landscape element, otherwise, when forest edges were absent, they mainly chose shaded lawns $\left(\chi^{2}\right.$ test, site 2, $\chi^{2}=60.96, d f=3, P<0.001$ and $\chi^{2}$ test, site 3 , $\left.\chi^{2}=6.48, d f=1, P=0.011\right)$.

Landscape selection map

In the $20 \times 20$ meters grid obtained (Fig. 2), $64 \%$ of the landscape area were selected lower than $40 \%$. Only $21 \%$

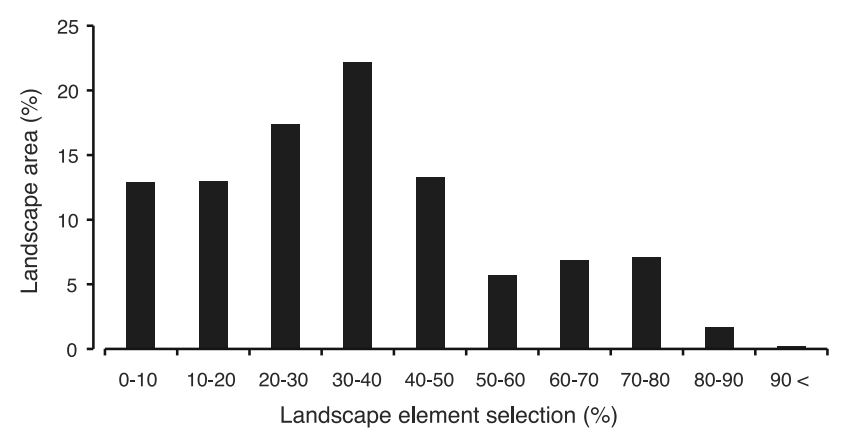

Fig. 5 Frequency of the landscape elements selection (\%) according to their area (\%) obtained by inter-patch movement modelling. Although the category ' $0-10$ ' includes the value of zero, other categories cover the range between the value above the lower limit and the value at the higher limit 
of landscape area had selection up to $50 \%$ (Fig. 5). Based on the ECOMOS classification of the putative presence of host plants, $29 \%$ of the landscape area were covered by habitat patches (i.e., $34 \%$ landscape elements among a total of 109 558). The mean selection (\%) of habitat patches was significantly higher $(24.73 \% \pm 20.23)$ than non habitat patches $(9.59 \% \pm 9.52)(t$ test, $t=138$, $P<0.001)$.

Mass-release-resighting experiment and graph modelling

A total of 110 butterflies were released in two MRS (26 in MRS 1 and 84 in MRS 2). 11 recapture events were recorded ( 3 coming from MRS 1 and 8 coming from MRS 2, Fig. 6). Euclidean distances between release and recapture sites varied from $120 \mathrm{~m}$ to $20.46 \mathrm{~km}$ and the latest recapture was made 18 days after the release.

We calculated the unchanged component rates (i.e., number of butterflies seen in the same component) using the 11 points where butterflies have been resighted and a random sample of 100 points for each released site (Fig. 4a).

The number of recaptures in the same graph components was 5 individuals (45\%) for MRS 1 and MRS 2. For the simulated data, the unchanged component rate was $14 \%$ (28 individuals). By comparing the unchanged component rates made by graph components between real and simulated data, we showed that resighted butterflies were significantly more often found in the same component than simulated individuals $\left(\chi^{2}\right.$ test, $\chi^{2}=5.62, d f=1$, $P=0.018)$.

The difference between these rates strongly varied according to the butterfly selection: the curve of Fig. $4 \mathrm{~b}$ shows that the difference was positive until a cost distance threshold of about 400, and then rapidly decreased to become negative. According to this curve, we chose the distance of 325 to compute the final landscape graph which better represented the real $P$. brassicae habitat connectivity network. By taking into account all the links having a least cost distance between 300 and 325, the corresponding value expressed in a metric unit was assessed to the average distance of $3.1 \mathrm{~km}$. This graph identified 9 main components in the landscape; the north of the region (8 components) being much more fragmented than the south (1 component) (Fig. 6a).

\section{Discussion}

Our results show that $P$. brassicae individuals mainly chose forest edges and shaded lawns to leave their release points, whereas open lawns were less frequently chosen. The availability of nectar sources, roosting sites and gradients of microclimatic conditions are key factors for the selection of flyways by dispersing butterflies (e.g., Dennis and Hardy 2007; Van Halder et al. 2008). In this study we simulated individual inter-patch movements to obtain the
Fig. 6 Map (a) of the 9 main components (surrounded by lines) and possible links (black lines) between suitable habitats (represented by circles with various diameters according to their areas). Resighting points of released butterflies are related to their release points ( 1 and 2 for MRS 1 and MRS 2 respectively) by black bold lines (For MRS 1 , two black bold lines are too short to be seen). Urbanized patches (in black) identified (b) by the ECOMOS 2003 classification in the Île-deFrance region (areas such as rural patches and open urban areas are represented in white)
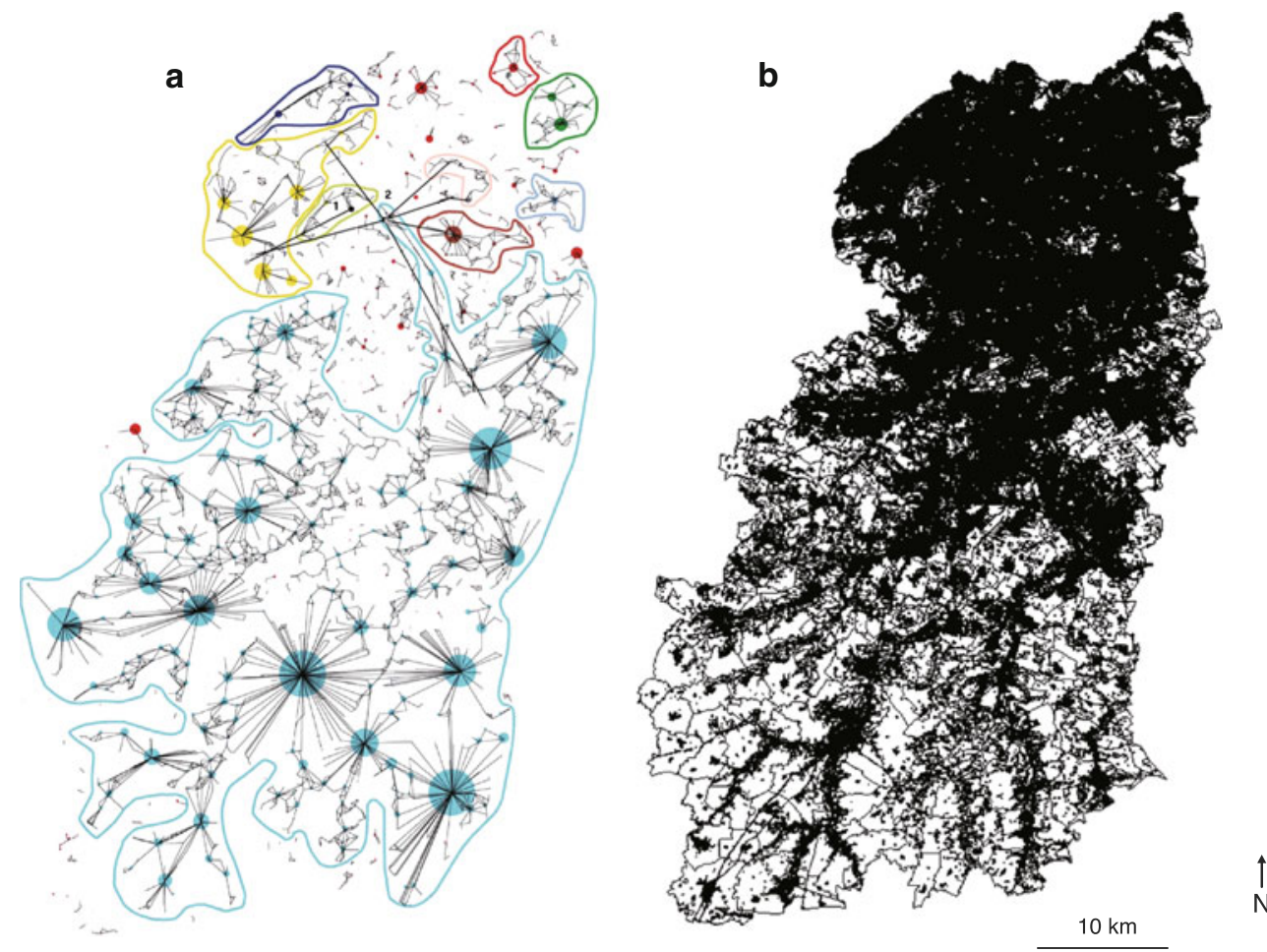
selection value for each landscape element. Selection of landscape elements varied widely in our urban region. This result clearly shows that butterfly movements might be hindered by hostile landscape elements in a densely urbanized region such as Île-de-France. Following Dennis and Hardy (2007), two types of flights have been identified for butterflies: "direct linear flight" regarded as dispersal flight and "search flight" regarded as resource seeking activity. Our inter-patch movement model was well suited to model "direct linear flight" between landscape elements because such displacements were shown to be widely used by $P$. brassicae individuals in cities (Dennis and Hardy 2007).

In this study, landscape elements classified as "Others" have no influence in the calculation of landscape element selection in the inter-patch movement model. Here, these landscape elements represented only $1.22 \%$ of the landscape elements considered and to our knowledge no other studies revealed an impact of such landscape elements on habitat selection in $P$. brassicae. Thus, we could easily consider here that potential bias induced by such choice was limited in our study. However, in other landscapes where "Others" landscape elements could be more numerous, care would need to be taken in the integration of such parameters.

Compared to more classical work on dispersal (e.g., analysis of movement paths or random walk simulations, Turchin 1998; Bowne and Bowers 2004), our method provides new insights in the understanding of dispersal behaviour by providing information how we can estimate inter-patch movement of organisms in an environment and also information on how we can estimate potential connectivity between habitat patches. Indeed, if random walk simulations within habitat patches provide a valuable tool for modelling routine movements (Schtickzelle and Baguette 2003), for dispersal movements between landscape elements at a larger scale, specific considerations are required (i.e., butterfly landscape element selection). Thus, as the contribution of routine movements to dispersal is expected to decline with the degree of habitat fragmentation (Van Dyck and Baguette 2005), we then used interpatch movement modelling to landscape graph to predict butterfly movements between habitat patches in our landscape. Methods based on such models are more appropriate to coarser spatio-temporal scale methods than random walk based methods (Turchin 1998) because both habitat patch distribution and the nature of the matrix were taken into account. It is particularly useful within the global change context where attention is currently paid to urbanization mediated landscape fragmentation (Stefanescu et al. 2004; Ockinger et al. 2009). In such kind of landscapes, featuring species' most important dispersal ways (i.e., ecological corridors, defined as spaces allowing species movements between two hospitable patches, Clobert et al. 2001) will favor the persistence of metapopulations by increasing compensations of local extinction by immigration in different landscape elements (Hanski 1999). But, in urban areas, factors such as strong boundary effect could limit dispersal between habitat patches (Thomas 2000; Merckx et al. 2003; Bergerot et al. 2012). In such a context, coupling inter-patch movement models with landscape graphs could be very useful to quantify boundary effects, to allow the measurement of each landscape element contribution to the overall connectivity (Urban and Keitt 2001; Saura and Pascual-Hortal 2007) and to integrate individual behaviours into population models (Morzillo et al. 2011). Indeed, the addition of parameters to our model could allow us to answer demographic questions. For example, by adding mortality and movement speed between landscape elements, we could generate specific predictions on how spatio-temporal density of butterflies will change on a short time scale.

By applying landscape graph to the study area, we identified 9 graph components where habitat patches of $P$. brassicae were well connected by permeable landscape elements. Our comparison between the unchanged component rates calculated from real and simulated resightings showed that really resighted butterflies were significantly more often found in the same component than simulated individuals. If $P$. brassicae is considered as a really vagile species (Bink 1992), the high number of graph components in more urban areas (Fig. 6) shows that urbanization can lead to the fragmentation of the landscape for this species. The mean dispersal distance within a component averaged to $3.1 \pm 2.12 \mathrm{~km}$. This distance was in accordance with the dispersal distance of the species recorded in the literature (Feltwell 1981). So, in the Île-de-France region, the matrix was not so "inhospitable" for $P$. brassicae within a component because our model (i.e., a combination between dispersal abilities and nature of the landscape between habitat patches) shows that the mean dispersal distance within a component was approximately the mean daily dispersal distance for this species. These results validate the hypothesis previously made by Bergerot et al. 2010a showing that dispersal abilities of $P$. brassicae allows the persistence of this species in this region. We show that the northern part of the study area, which is also the most urbanized, is much more fragmented than its southern part (Fig. 6a). The largest graph component identified in the south could be explained by the nature of the landscape elements. Indeed, urbanized areas are there mainly interspersed with rural areas (Fig. 6b), which facilitate butterfly movements.

Our aim was here to show how combining inter-patch movement models and landscape graph-based approach could provide an efficient tool to assess functional 
connectivity in large areas by validating the results obtained from this model with empirical data. According to Urban et al. (2009) the validation of these models with independent data is crucial. But in practice, several studies using patch-based graph models suffer from a lack of validation (Galpern et al. 2011). Providing this empirical validation is not always feasible because of the difficulties to obtain information about dispersal events in the field. Combination of models such as inter-patch movement or individual based models and landscape graphs is a useful alternative to tackle this problem (Lookingbill et al. 2010; Morzillo et al. 2011). Fortunately, the biological model used in this study allows us to get field observation with mass-release-resighting experiment. However, particular attention has to be paid to our small number of resightings, which forced us to combine the data from two different sites. Indeed, statistical power to compare the rate of recapture in the same component between recapture data and simulated data is weak if we consider sites independently. Only a global comparison is possible in our case which limited our validation process. We are conscious of the lack of real recapture events to fully validate our model. However, even if $45 \%$ of our real resights were made in intra-components defined by our model (concerning only 11 individuals), a significant difference with the random model was noticed. We could expect that the percentage of intra-component resights would increase with the number of individuals in the mass release experiment. If more resightings had been available from more release sites, it would have been possible to extend the conclusions of the study by prioritizing their relative contributions to the connectivity within their components.

This study reveals an appealing feature of the landscape graph framework, i.e., the possibility of building maps of functional connectivity and explore their structure with small empirical data sets.

Acknowledgments We particularly thank volunteers for their observation and participation to the study and Natureparif, Audrey Coulon for the caterpillars rearing, Leyli Borner and all the Evoltrait team based in Brunoy for their support and useful help in this study. We especially thank the two anonymous reviewers whose comments greatly improved this manuscript. MB's contribution was funded by a grant from the ANR (Agence Nationale de la Recherche, Open Call DIAME 2008-2011 DIspersal And MEtapopulations). This project was supported by the SCALE project. The graph analysis was conducted in the framework of the Graphab project of the USR 3124 MSHE Ledoux, funded by the French Ministry of Ecology, Energy, Sustainable Development and Sea.

\section{References}

Andersson E, Bodin O (2009) Practical tool for landscape planning? An empirical investigation of network based models of habitat fragmentation. Ecography 32:123-132
Baguette M, Van Dyck H (2007) Landscape connectivity and animal behavior: functional grain as a key determinant for dispersal. Landsc Ecol 22:1117-1129

Bergerot B, Julliard R, Baguette M (2010a) Metacommunity dynamics: decline of functional relationship along a habitat fragmentation gradient. PLoS ONE 5(6):e11294. doi:10.1371/journal.pone. 0011294

Bergerot B, Fontaine B, Renard M, Cadi A, Julliard R (2010b) Preferences for exotic flowers do not promote urban life in butterflies. Landsc Urban Plan 96:98-107

Bergerot B, Merckx T, Van Dyck H, Baguette M (2012) Habitat fragmentation impacts mobility in a common and widespread woodland butterfly: do sexes respond differently? BMC Ecology 12(5). doi:10.1186/1472-6785-12-5

Bink BA (1992) Ecologische atlas van de Dagvlinders van Noordwest-Europa (Ecological Atlas of the Butterflies of NW Europe). Schuyt \& Co, Haarlem

Bowne DR, Bowers MA (2004) Interpatch movements in spatially structured populations: a literature review. Landsc Ecol 19:1-20

Bunn AG, Urban DL, Keitt TH (2000) Landscape connectivity: a conservation application of graph theory. J Environ Manage 59:265-278

Clobert J, Danchin E, Dhont AA, Nichols JD (2001) Dispersal. Oxford University Press, New York

Clobert J, Le Gaillard JF, Cote J, Meylan S, Massot M (2009) Informed dispersal, heterogeneity in animal dispersal syndromes and the dynamics of spatially structured populations. Ecol Lett 12:197-209

Dennis RLH, Hardy PB (2007) Support for mending the matrix: resource seeking by butterflies in apparent non-resource zones. J Insect Conserv 11:157-168

ECOMOS (2003) Ecological Soil Occupation Mode. See: http://www. iau-idf.fr/lile-de-france/un-portrait-par-les-chiffres/occupation-dusol.html

Fahrig L (2003) Effects of habitat fragmentation on biodiversity. Annu Rev Ecol Evol Syst 34:487-515

Fahrig L, Merriam G (1994) Conservation of fragmented populations. Conserv Biol 8:50-59

Fall A, Fortin MJ, Manseau M, O'Brien D (2007) Spatial graphs: principles and applications for habitat connectivity. Ecosystems 10:448-461

Feltwell J (1981) Large white butterfly: the biology, biochemistry, and physiology of Pieris Brassicae. DRW junk publishers, The Hague

Foltête J-C, Clauzel C, Vuidel G, Tournant P (2012) Integrating graph-based connectivity metrics into species distribution models. Landsc Ecol 27:557-559

Galpern P, Manseau M, Fall A (2011) Patch-based graphs of landscape connectivity: a guide to construction, analysis and application for conservation. Biol Conserv 144:44-55

Haddad NN (1999) Corridor and distance effects on interpatch movements: a landscape experiment with butterflies. Ecol Appl 9:612-622

Haddad NN, Tewksbury JJ (2005) Low-quality habitat corridors as movement conduits for two butterfly species. Ecol Appl 15:250-257

Hanski I (1999) Metapopulation ecology. Oxford University Press, New York

Laita A, KotiahoJ Mönkkönen M (2011) Graph-theoretic connectivity measures: what do they tell us about connectivity? Landsc Ecol 26:951-967

Lookingbill TR, Gardner RH, Ferrari JR, Keller CE (2010) Combining a dispersal model with network theory to assess habitat connectivity. Ecol Appl 20:427-441

Merckx T, Van Dyck H, Karlsson B, Leimar O (2003) The evolution of movements and behaviour at boundaries in different 
landscapes: a common arena experiment with butterflies. Proc R Soc B 270:1815-1821

Minor ES, Lookingbill TR (2010) A multiscale network analysis of protected-area connectivity for mammals in the United States. Conserv Biol 24:1549-1558

Morrison ML, Hall LS (2002) Standard terminology: toward a common language to advance ecological understanding and application. In: Scott JM, Heglund P, Morrisson ML, Raven PH (eds) Predicting species occurrences. Issues of accuracy and scale. Island Press, Washington, pp 43-52

Morzillo AT, Ferrari JR, Liu JG (2011) An integration of habitat evaluation, individual based modeling, and graph theory for a potential black bear population recovery in southeastern Texas, USA. Landsc Ecol 26:69-81

O'Brien D, Manseau M, Fall A, Fortin MJ (2006) Testing the importance of spatial configuration of winter habitat for woodland caribou: an application of graph theory. Biol Conserv 130:70-83

Ockinger E, Dannestam A, Smith HG (2009) The importance of fragmentation and habitat quality of urban grasslands for butterfly diversity. Landsc Urban Plan 93:31-37

Saura S, Pascual-Hortal L (2007) A new habitat availability index to integrate connectivity in landscape conservation planning: comparison with existing indices and application to a case study. Landsc Urban Plan 83:91-103

Schtickzelle N, Baguette M (2003) Behavioural responses to habitat patch boundaries restrict dispersal and generate emigration-patch area relationships in fragmented landscapes. J Anim Ecol 72:533-545

Spear SF, Balkenhol N, Fortin MJ, McRae BH, Scribner K (2010) Use of resistance surfaces for landscape genetic studies: considerations for parameterization and analysis. Mol Ecol 19:3576-3591
Stefanescu C, Herrando S, Paramo F (2004) Butterfly species richness in the north-west Mediterranean Basin: the role of natural and human-induced factors. J Biogeogr 31:905-915

Stevens VM, Verkenne C, Vandewoestijne S, Wesselingh RA, Baguette M (2006) Gene flow and functional connectivity in the natterjack toad. Mol Ecol 15:2333-2344

Stevens VM, Turlure C, Baguette M (2010) A meta-analysis of dispersal in butterflies. Biol Rev 85:625-642

Storfer A, Murphy MA, Spear SF, Holderegger R, Waits LP (2010) Landscape genetics: where are we now? Mol Ecol 19:3496-3514

Taylor PD, Farhig L, Henein K, Merriam G (1993) Connectivity is a vital element of landscape structure. Oikos 68:571-572

Thomas CD (2000) Dispersal and extinction in fragmented landscapes. Proc R Soc B 267:139-145

Turchin P (1998) Quantitative analysis of movement: measuring and modeling population redistribution in animals and plants. Sinauer Associates Inc, Sunderland

Urban D, Keitt T (2001) Landscape connectivity: a graph-theoretic perspective. Ecology 82:1205-1218

Urban D, Minor ES, Treml EA, Schick RS (2009) Graph models of habitat mosaics. Ecol Lett 12:260-273

Van Dyck H, Baguette M (2005) Dispersal behaviour in fragmented landscapes: routine or special movements? Basic Appl Ecol 6:535-545

Van Halder I, Barbaro L, Corcket E, Jactel H (2008) Importance of semi-natural habitats for the conservation of butterfly communities dominated by pine plantations. Biodivers Conserv 5:1149-1169

Wilcove DS, McLellan CH, Dobson AP (1986) Habitat fragmentation in the temperate zone. In: Soulé ME (ed) Conservation biology: the science of scarcity and diversity. Sinauer Assoc, Sunderland, pp 237-256 